\title{
SpPKE1, a Multiple Stress-Responsive Gene Confers Salt Tolerance in Tomato and Tobacco
}

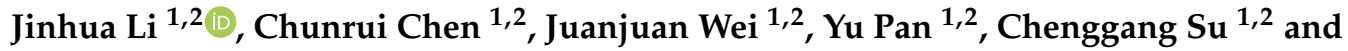 \\ Xingguo Zhang ${ }^{1,2, *}$ \\ 1 State Cultivation Base of Crop Stress Biology for Southern Mountainous land of Southwest University, \\ Academy of Agricultural Sciences, Southwest University, Beibei, Chongqing 400715, China; \\ ljh502@swu.edu.cn (J.L.); eline1020@email.swu.edu.cn (C.C.); shucaitomato@gmail.com (J.W.); \\ pany1020@swu.edu.cn (Y.P.); suchenggang@swu.edu.cn (C.S.) \\ 2 Key Laboratory of Horticulture Science for Southern Mountainous Regions, Ministry of Education, \\ College of Horticulture and Landscape Architecture, Southwest University, No.2 Tiansheng Road, Beibei, \\ Chongqing 400715, China \\ * Correspondence: zhangdupian@swu.edu.cn; Tel.: +86-23-68250974; Fax: +86-23-68251274
}

Received: 29 April 2019; Accepted: 17 May 2019; Published: 20 May 2019

\begin{abstract}
Understanding the mechanism of abiotic-tolerance and producing germplasm of abiotic tolerance are important in plant research. Wild species often show more tolerance of environmental stress factors than their cultivated counterparts. Genes from wild species show potential abilities to improve abiotic resistance in cultivated species. Here, a tomato proline-, lysine-, and glutamic-rich type gene SpPKE1 was isolated from abiotic-resistant species (Solanum pennellii LA0716) for over-expression in tomato and tobacco for salt tolerance. The protein encoded by SPPKE1 was predominantly localized in the cytoplasm in tobacco. SpPKE1 and SIPKE1 (from cultivated species S. lycopersicum cv. M82) shared $89.7 \%$ similarity in amino acid sequences and their transcripts abundance in flowers and fruits was reduced by the imposition of drought or oxidative stress and the exogenous supply of abscisic acid. The DNA of the PKE1 promoter was highly methylated in fruit and leaf, and the methylation of the coding sequence in leaf was significantly higher than that in fruit at different development stages. The over-expression of SPPKE1 under the control of a CaMV (Cauliflower Mosaic Virus) 35S promoter in transgenic tomato and tobacco plants enhanced their tolerance to salt stress. PKE1 was downregulated by abiotic stresses but enhanced the plant's salt stress tolerance. Therefore, this gene may be involved in post-transcriptional regulation and may be an important candidate for molecular breeding of salt-tolerant plants.
\end{abstract}

Keywords: abiotic stress; salt stress; proline-, lysine-, and glutamic-rich protein; wild tomato species; tobacco

\section{Introduction}

Plant growth and development are continuously influenced by environmental factors, including water content, salinity, and temperature, which may disrupt plant homeostasis. The tomato plant belongs to the Solanaceae family. It is mainly cultivated as edible fruit and is a kind of vegetable crop which can be commercially grown worldwide (FAOSTAT 2013). Production and consumption of tomato has been increasing continuously [1]. Although some available tomato germplasms possess tolerance for various abiotic stresses, crop losses will become severe under extreme climatic conditions. Domestication, selection, and different breeding methods have narrowed down the genetic diversity of cultivated tomato. Therefore, developing new high-yielding cultivars, that are tolerant to various abiotic stresses, will substantially influence tomato production [2]. 
Transgenic plants with engineered endogenous genes produce abiotic stress-tolerant phenotypes in tomato. These genes affect abiotic stress tolerance. S. lycopersicum ethylene response factor B.3 (Sl-ERF.B.3) gene encodes for a tomato ethylene-responsive element binding factor (ERF) transcription factor, whereas Sl-ERF.B.3 antisense transgenic plants exhibit salt- and cold-stress-dependent growth inhibition [3]. A tomato class II ERF protein SIERF3 also plays an important role in crop improvement or genetic engineering by increasing stress tolerance in plants [4]. Tomato-dehydration-responsive element binding two transcription factors enhances plant tolerance to salinity in tomato and Arabidopsis [5]. Similarly, the tomato zinc finger2 cysteine-2/histidine-2 repressor-like transcription factor confers tolerance to salinity in tomato and Arabidopsis [6]. A tomato bZIP protein named abscisic acid-responsive element binding protein (AREB1) is responsive to abscisic acid (ABA) and it increases the salt and water loss resistance of the tomato plant [7]. Functional proteins such as $\mathrm{Na}^{+} / \mathrm{H}^{+}$antiporter SISOS1 and $\mathrm{K}^{+} / \mathrm{H}^{+}$antiporter $\mathrm{NHX} 2$ are also successfully used to improve tomato salt stress tolerance [8-10]. Transgenic tomato plants with overexpressed AtNHX1 increased the capacity to retain intracellular $\mathrm{K}^{+}$ and confer salt stress tolerance [11]. The ectopic expression of tomato SITIP2;2 can enhance tolerance to salt stress in Arabidopsis [12]. In some cases, genes negatively function in abiotic stress resistance. For example, NAC transcription factor SISRN1 of tomato is not only a negative regulator for oxidative and drought stress response [13], but also a negative regulator of salt and oxidative stresses as a kind of hybrid proline-rich protein (PRP) [14].

In this study, we isolated a proline-, lysine-, and glutamic-rich protein gene (PKE) from drought-resistant species (S. pennellii LA0716) and cultivated species (S. lycopersicum cv. M82) and named as SPPKE1 and SIPKE1 respectively. PKE1 was differentially expressed after drought treatment of S. lycopersicum cv. M82 and S. pennellii LA0716 [15]. Then, expression and function of this gene were analyzed. PKE1 is suppressed by various abiotic stresses, including dehydration, oxidative stress, and phytohormones ABA and salicylic acid (SA). Over-expression (OE) of SpPKE1 can significantly enhance salt tolerance of tomato and tobacco. DNA of the PKE1 coding sequence in leaf is methylated higher than that in fruit at different development stages. This research work will shed more light on the molecular mechanism of PKE1, which is down-regulated by stress but plays a positive role in stress tolerance.

\section{Results}

\subsection{Characterization of PKE1 in Tomato}

In a previous study of drought stress in tomato introgression lines [15], a differential expression profile of the PKE1 gene was observed between the drought-tolerant introgression line (IL) and M82. After drought stress, the expression of PKE1 significantly decreased in M82, IL2-5 and IL9-1 (Figure S1). Full-length PKE1 cDNAs were isolated from S. lycopersicum cv. M82 and S. pennellii LA0716 by reverse transcription (RT)-PCR and labelled as SIPKE1 and SPPKE1 respectively. SIPKE1 and SpPKE1 encoded 326 and 319 amino acids respectively, which shared 89.7\% similarity (Figure 1A). Proline in SIPKE1 and SpPKE1 accounted for $18.7 \%$ and $18.5 \%$ of the total amino acid residues respectively, followed by lysine $(17.2 \%$ and $16.3 \%)$ and glutamate $(12.3 \%$ and $11.2 \%)$. The proline, lysine and glutamate acid residues in SIPKE1 and SpPKE1 accounted for $48.2 \%$ and $46.1 \%$ of the total residues respectively (Table S1). According to tomato genomic sequence, SIPKE1 and SPPKE1 both contain two introns and three exons, but have difference in nucleotide lengths of the third exon (Figure 1B). Hence, PKE1 is conserved in wild and cultivated plant species and code divergent amino acids. The phylogenetic tree, constructed based on the amino acid sequences of PKE1 and PKE proteins from other representative organisms, demonstrated that SIPKE1 and SpPKE1 were evolutionarily closely related to those PKEs, isolated from other Solanaceae plants (S. tuberosum and S. chacoense) (Figure 1C). These results implied that PKE1 might have similar functions as other PKE proteins, isolated from Solanaceae plants. 


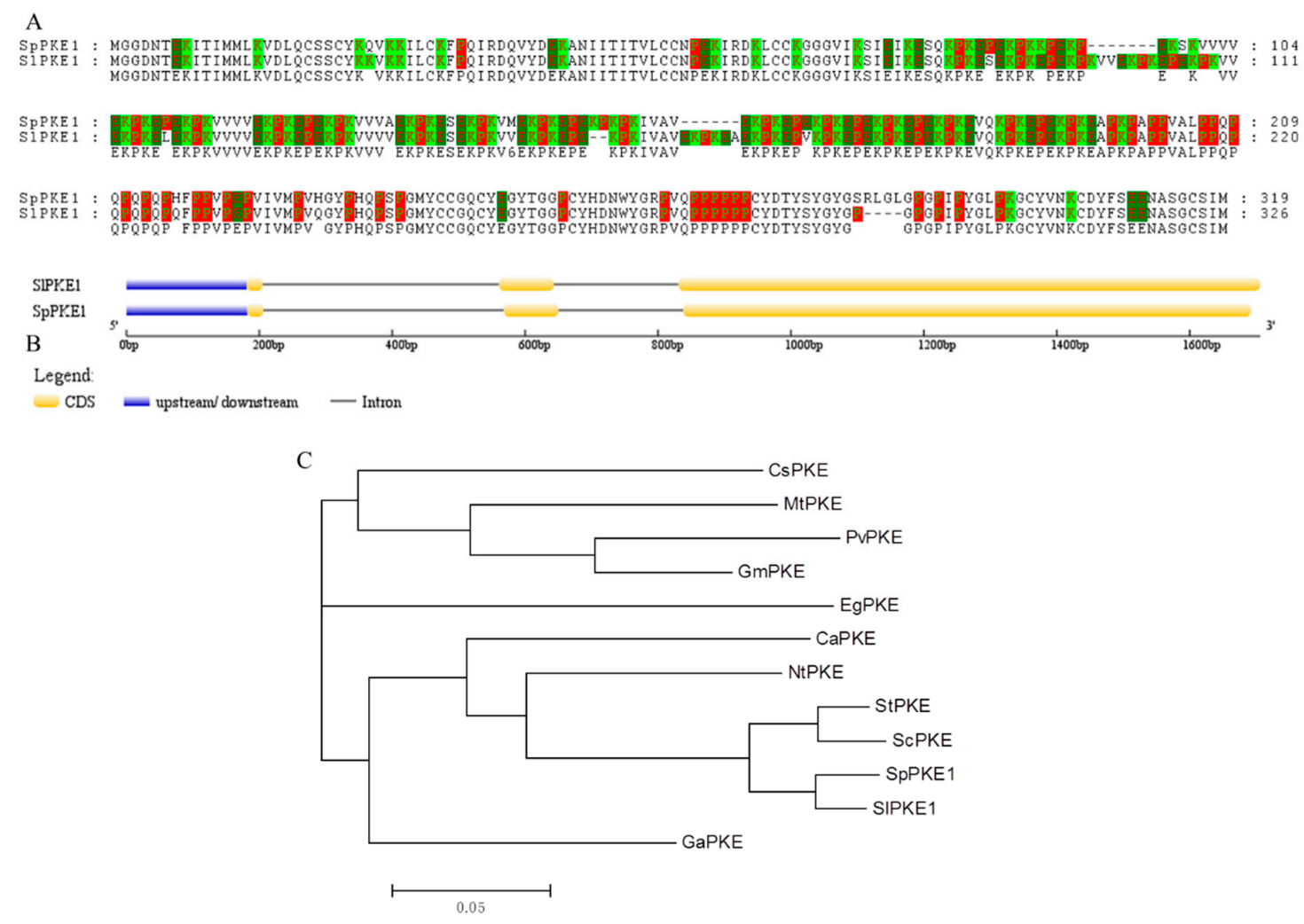

Figure 1. Comparison of amino acid sequence and phylogenetic analyses of PKE1. (A) Amino acid alignment of S. lycopersicum cv. M82 (SIPKE1) and S. pennellii LA0716 (SpPKE1). (B) Gene structure of the tomato SIPKE1 and SPPKE1 generated from Gene Structure Display Server (GSDS). The yellow block indicates the coding sequence (CDS), the blue block refers to upstream or downstream of the genes, the black line represents the intron. Scale bar indicates the DNA sequence length. (C) Neighbor Joining tree for SIPKE1, SpPKE1 and PKE1 from their highest similarity proteins in the EBI (European Bioinformatics Institute) database. The PKE1 from other species are as follows: CsPKE1 (Citrus sinensis: A0A067GT86), MtPKE1 (Medicago truncatula1: G7JMW9), PvPKE1 (Phaseolus vulgaris: V7CAV2), GmPKE1 (Glycine max: I1MQY4), EgPKE1 (Erythranthe guttata: A0A022QI88), CaPKE1 (Capsicum annuum: Accession no. O81922), NtPKE1 (Nicotiana tabacum: A0A1S4A831), StPKE1 (Solanum tuberosum: M1AFN1), ScPKE1 (Solanum chacoense: A0A0V0I462) and GaPKE1 (Gossypium arboretum: A0A0B0MHK6).

Cis-elements participate in gene regulation by interacting with their corresponding trans-regulatory factors. Hence, the promoter regions of SPPKE1 and SIPKE1 were retrieved and submitted to the PlantCARE database for cis-element identification (Table 1). Conventional promoter elements (TATA-box and CAAT-box) were detected in PKE1 promoters. The remaining cis-acting elements can be divided into four groups. Six cis-elements, Box 4, ARE (only in SIPKE1), AE-box, ATCT-motif, LAMP-element (special appeared in SlPKE1), and TCT-motif, were light-responsive. Three cis-elements, CGTCA-motif, TGACG-motif, and TCA-element (only in SIPKE1), were hormone-responsive. Five cis-elements, TC-rich repeats, LTR (only in SpPKE1), MYB, MYB-like sequence, and MYC, functioned as stress-responsive elements. The fourth group had a HD-Zip 1 cis-element, which was involved in the differentiation of palisade mesophyll cells. 
Table 1. The cis-elements identified in the promoters of SIPKE1 (in M82) and SpPKE1 (in S. pennellii) and the differences of their cis-elements.

\begin{tabular}{|c|c|c|}
\hline S. pennellii & M82 & Functions of cis-elements \\
\hline 5UTR Py-rich stretch & 5UTR Py-rich stretch & \\
\hline AAGAA-motif & AAGAA-motif & \\
\hline AC-II & AC-I & \\
\hline \multirow[t]{2}{*}{ AE-box } & AE-box & \\
\hline & $\star \mathrm{ARE}$ & $\begin{array}{l}\text { cis-acting regulatory element essential for the } \\
\text { anaerobic induction }\end{array}$ \\
\hline \multirow[t]{2}{*}{ AT-rich element } & AT-rich element & \\
\hline & $\star$ AT1-motif & part of a light responsive module \\
\hline \multirow[t]{2}{*}{ ATCT-motif } & ATCT-motif & \\
\hline & $\star$ ATGCAAAT motif & $\begin{array}{c}\text { cis-acting regulatory element associated to the } \\
\text { TGAGTCA motif }\end{array}$ \\
\hline Box 4 & Box 4 & \\
\hline Box I & Box I & \\
\hline Box-W1 & Box-W1 & \\
\hline \multirow[t]{3}{*}{ CAAT-box } & CAAT-box & \\
\hline & $\star$ CGTCA-motif & $\begin{array}{l}\text { cis-acting regulatory element involved in the } \\
\text { MeJA-responsiveness }\end{array}$ \\
\hline & $\star$ GA-motif & part of a light responsive element \\
\hline GAG-motif & GAG-motif & \\
\hline GT1-motif & GT1-motif & \\
\hline HSE & HSE & \\
\hline \multirow[t]{2}{*}{ 次R } & & $\begin{array}{l}\text { cis-acting element involved in } \\
\text { low-temperature responsiveness }\end{array}$ \\
\hline & $\star \mathrm{I}$-box & part of a light responsive element \\
\hline O2-site & O2-site & \\
\hline Skn-1_motif & Skn-1_motif & \\
\hline Sp1 & Sp1 & \\
\hline TATA-box & TATA-box & \\
\hline TC-rich repeats & TC-rich repeats & \\
\hline TCA-element & TCA-element & \\
\hline \multirow[t]{2}{*}{ TCT-motif } & TCT-motif & \\
\hline & $\star$ TGACG-motif & $\begin{array}{l}\text { cis-acting regulatory element involved in the } \\
\text { MeJA-responsiveness }\end{array}$ \\
\hline W box & W box & \\
\hline circadian & circadian & \\
\hline
\end{tabular}

\subsection{SPPKE1 Localizes to the Cytoplasm}

To determine the sub-cellular localization of SpPKE1, we fused the full-length open reading frame of SpPKE1 with the N-terminal of a green fluorescent protein (GFP) reporter protein driven by CaMV $35 S$ promoter and generated a fusion protein SpPKE1-GFP. The fusion protein was infiltrated into tobacco suspension cells. Microscopic observation demonstrated that green fluorescence in the 
transformed cell was mainly localized in the cytoplasm, whereas no fluorescence was detected in non-transformed cells. Besides fluorescence was displayed throughout their structures (Figure 2) in those cells, which were transformed with the vector containing only GFP.

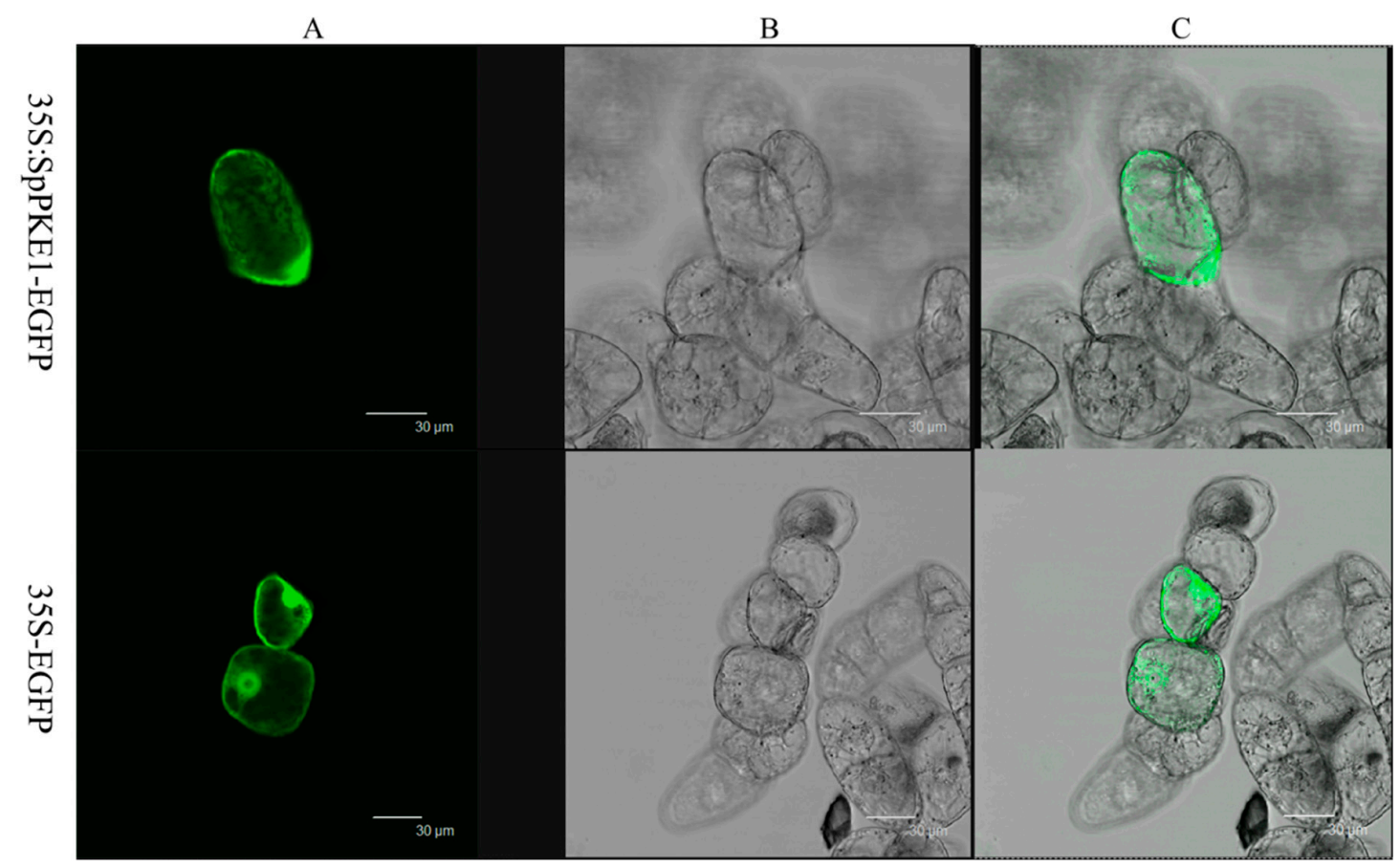

Figure 2. Subcellular localization of SpPKE1 in cv BY-2 tobacco cells. CaMV 35S::EGFP and 35S::SpPKE1-EGFP constructs were expressed transiently in cv BY-2 tobacco cells. Green fluorescent protein (GFP) fluorescence images (A), Bright-field images (B), and merged images (C) of representative cells transformed with 35S::EGFP or 35S::SpPKE1-EGFP fusion protein.

\subsection{PKE1 Expression Suppression by Abiotic Stress and Hypermethylation in Different Tissues}

RT-PCR analysis showed similarity of PKE1 tissue expression between S. pennellii and S. lycopersicum cv. M82. Indeed, PKE1 was highly expressed in flower and fruit, while a lower expression was observed in root and leaf (Figure 3A,B). DNA methylation analysis indicated that PKE1 promoter and the coding sequences were highly methylated, and accordingly with gene expression, methylation was significantly higher in the leaf compared to flower and fruit (Figure 3C and File S1). Interestingly, PKE1 expression was significantly suppressed by various abiotic stresses, including drought, methyl viologen (MV), ABA, and SA (Figure 4). Under drought, MV, GA3, and SA treatments, PKE1 expression was gradually reduced, and S. pennellii and S. lycopersicum cv. M82 showed similar expression patterns. However, PKE1 expression returned to pre-treatment levels after $24 \mathrm{~h}$ from ABA and Eth treatment. Under ABA treatment, PKE1 expression was significantly suppressed after $1 \mathrm{~h}$ of treatment in S. pennellii, while none variation in gene expression was observed in S. lycopersicum cv. M82. By contrast, under Eth treatment, PKE1 expression was significantly suppressed after $1 \mathrm{~h}$ of treatment in tomato cv. M82 but did not exhibit response in S. pennellii. 

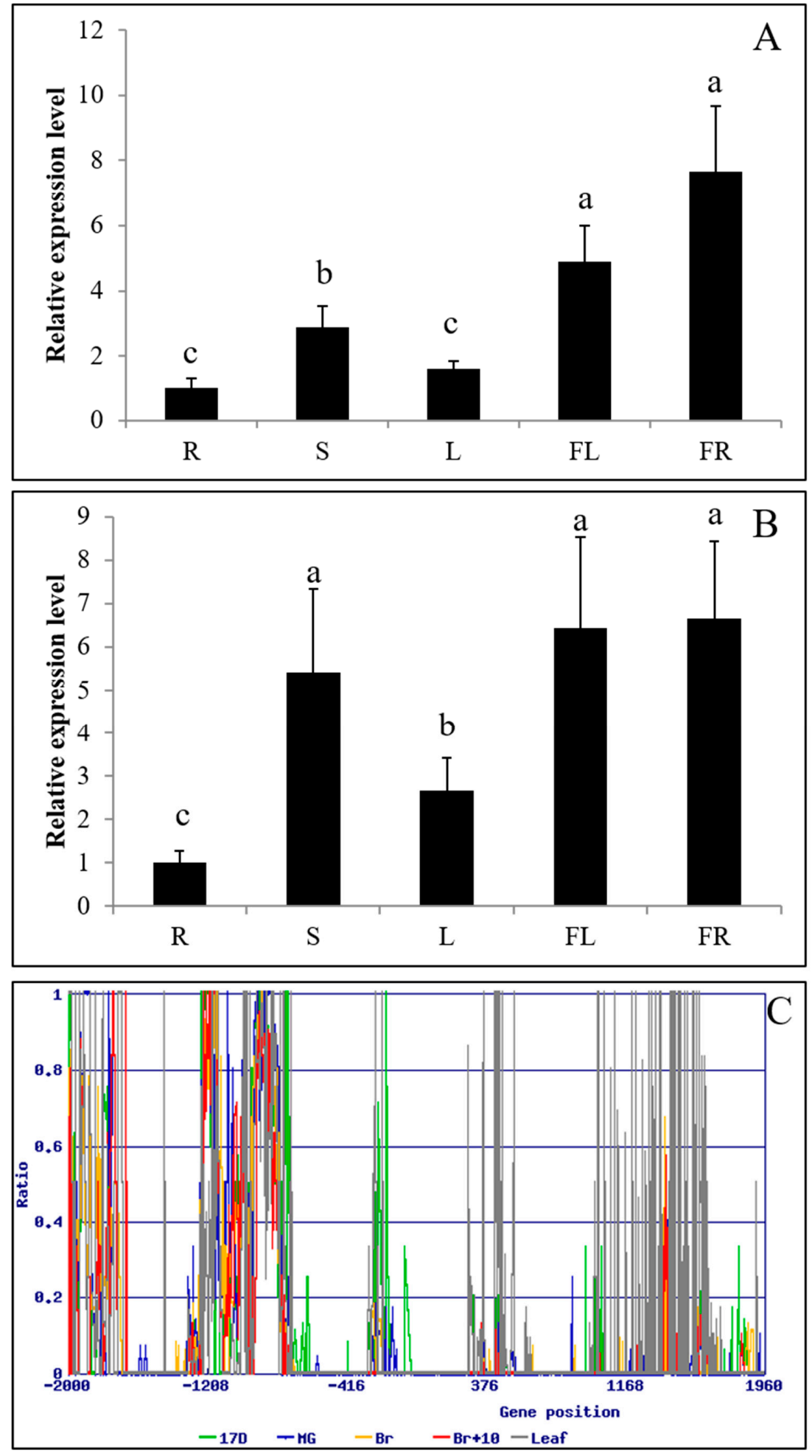

Figure 3. Tissue expression and methylation analysis of PKE1: gene expression profile in different tissues (R: root, S: stem, L: leaf, FL: flower, FR: fruit) of S. pennellii LA0716 (A) and S. lycopersicum cv. M82 (B). All samples were collected at the indicated time points from three biological replicates for each treatment condition. Error bars indicate \pm SE of means at $p<0.05(n=3)$. (C) Analysis of the DNA methylation of PKE1 promoter and coding sequences at different tissues and stages. Immature (17 DPA), mature green (MG: $39 \mathrm{DPA})$, breaker (Br: $42 \mathrm{DPA})$, and red ripe (Br+10: $52 \mathrm{DPA})$, and leaf. Ratio $=5 \mathrm{mC} /(5 \mathrm{mC}+\mathrm{C})$. 


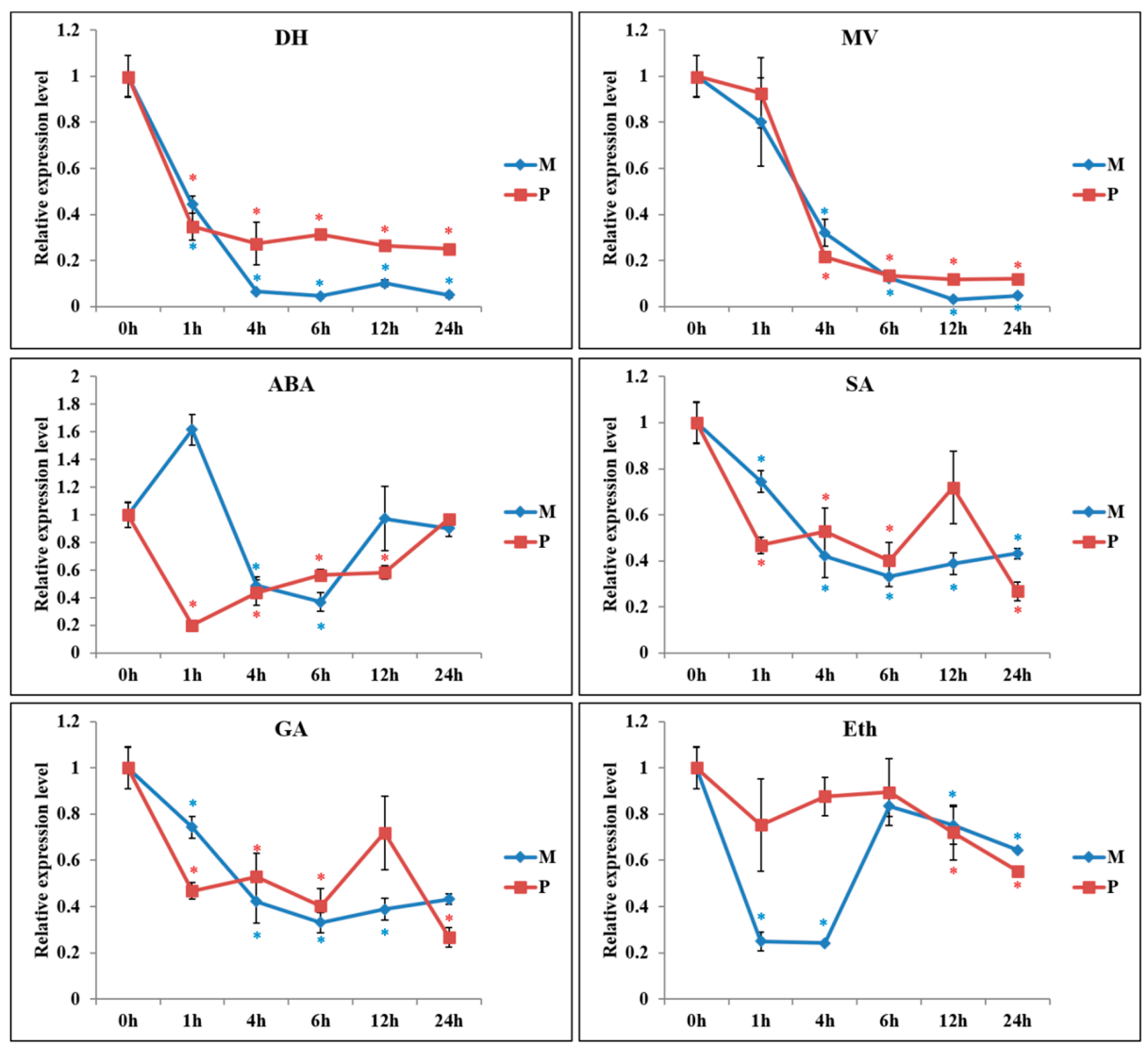

Figure 4. Expression pattern of tomato PKE1 under drought dehydration (DH), methyl viologen (MV), ABA (Abscisic acid), gibberellic acid ( $\left.\mathrm{GA}_{3}\right), \mathrm{SA}$ (salicylic acid), ethephon (Eth; an ethylene releaser) treatment in S. lycopersicum cv. M82 (M) and Solanum pennellii LA0716 (P). All samples were collected at the time points (' $\mathrm{h}$ ' refers to hours) after treatment from three biological replicates of each treatment. Data shown are means \pm SE $(n=3) *$, Means differ $p<0.05$.

\subsection{PKE1 Overexpression Enhanced Tolerance to Salt Stress}

Salt tolerance was examined in PKE1 overexpression (OE) and RNAi-konckdown (Ri) transgenic plants. The significant PKE1 OE plants (OE2 and OE5) and knockdown PKE1-RNAi plants (Ri1) were selected for further analysis. As shown in Figure 5, the SPPKE1 OE lines presented significantly enhanced salt tolerance, and the Ri1 was more sensitive compared to wild type (WT) lines. After salt treatment, less leaf necrosis and increasing shoot biomass was observed in transgenic OE plant lines. The survival rate in OEs (OE2: 79\% and OE5: 75\%) is higher than that in WT (33\%) and Ri (8\%). The result indicates that tomato transformed with the SpPKE1 gene displayed salt tolerance.

For further functional analysis of PKE1, 31 PKE1 OE transgenic tobacco plants were generated, and expression level transgenic plants was examined. PKE1 with significant differential expression compared with wild type (WT) and OE (OE20, OE28 and OE31) plants were selected for further analysis. No morphological difference was noted between the transgenic lines and WT (data not shown). The seedling shifted to the high salt for treatment for 7 days, the WT seedling leaves started to turn yellow, and the transgenic OE plant remained green (Figure 6A). After 12 days of treatment, the length of the root was significantly reduced. However, this reduction was significantly higher in WT lines than in SpPKE1-overexpressing plants (Figure 6B). Moreover, the content of chlorophyll was determined. Figure $6 \mathrm{C}$ shows that the chlorophyll contents of $\mathrm{OE}$ lines were significantly higher than those of WT plants under salt stress. Malondialdehyde (MDA) content was also determined under salt stress in WT and transgenic plants. As it is shown in the Figure 6D, MDA increased in WT and transgenic lines after salt treatment. However, this increase in salt-stressed WT lines was significantly 
higher than that in SpPKE1 OE plants. It indicates that the SpPKE1 OE plant inhibited the increase of MDA content under salt stress.

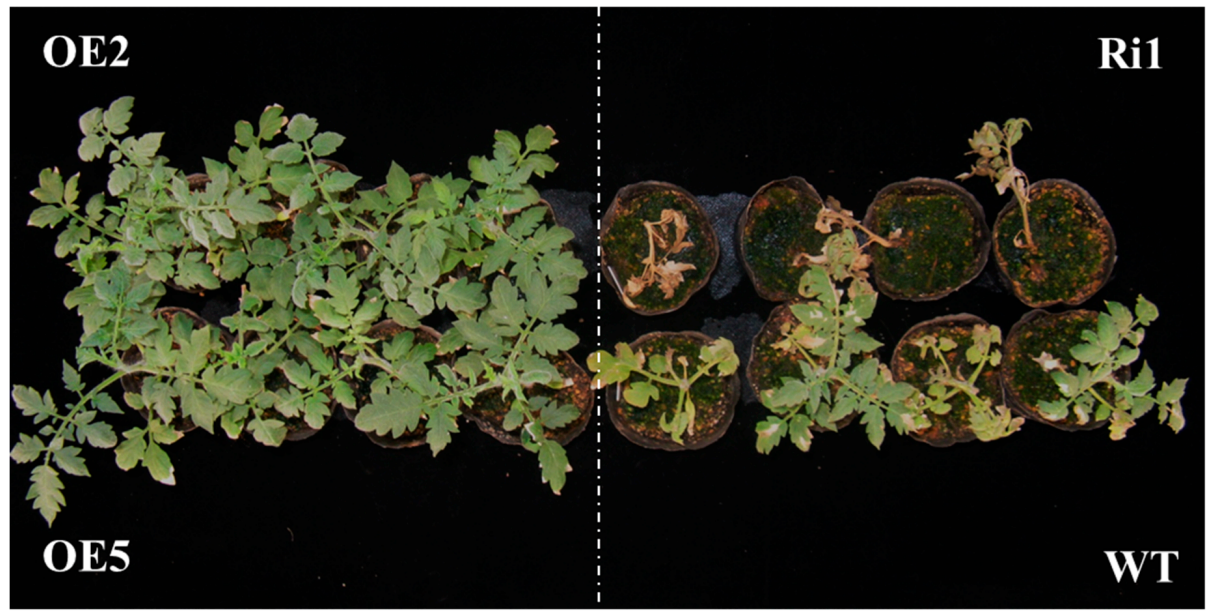

Figure 5. Seedling phenotype of tomato with overexpressed PKE1 (OE) and RNAi knockdown (Ri) under salt stress conditions. Four-leaf stage seedlings for salt treatment initiated by watering $200 \mathrm{mM}$ $\mathrm{NaCl}$ for $14 \mathrm{~d}$.
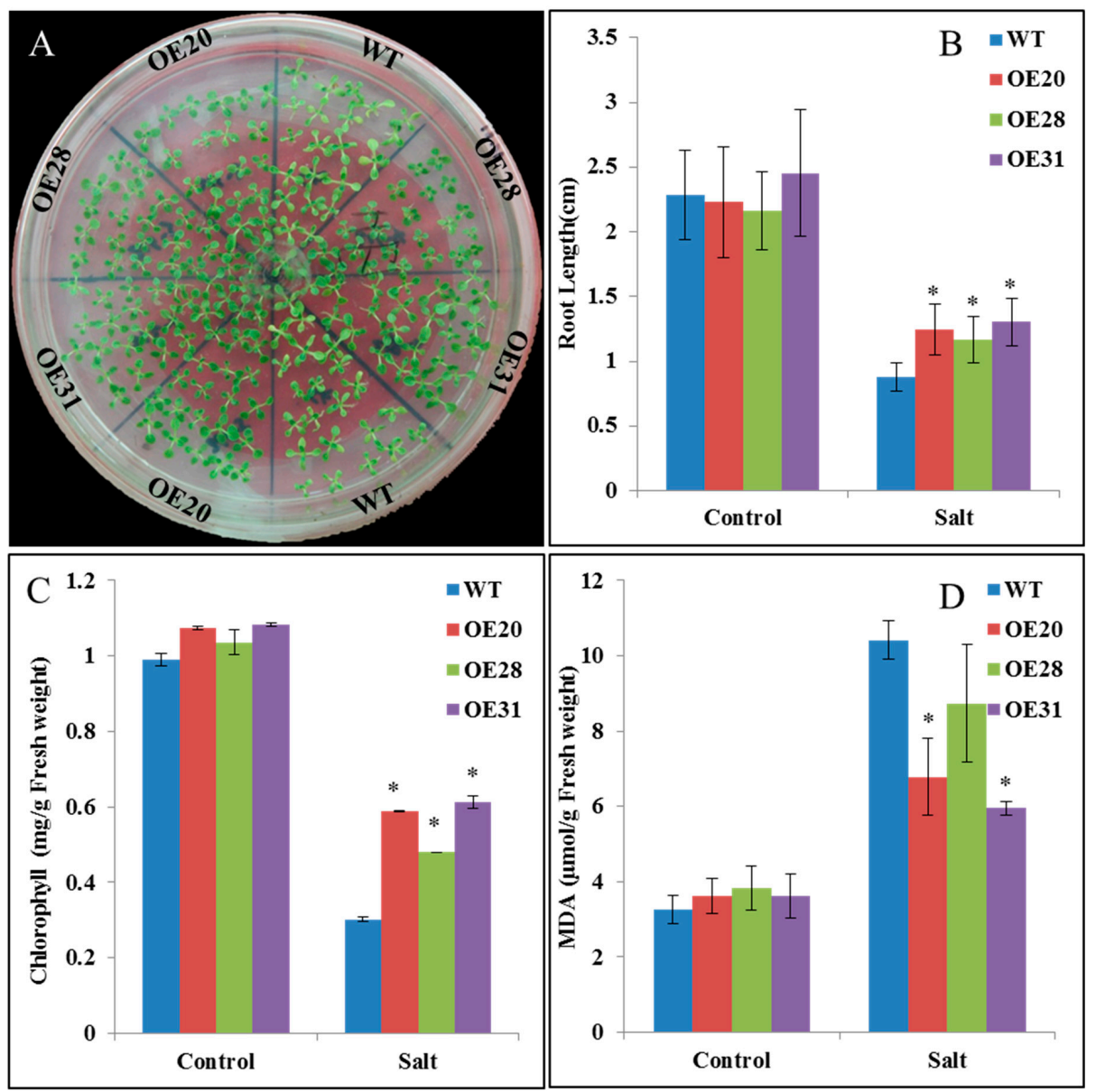

Figure 6. The overexpression (OE) of PKE1 in tobacco enhanced its salt tolerance. (A) OE of tobacco SPPKE1 lines and wild type (WT) subjected to $200 \mathrm{mM} \mathrm{NaCl}$. The image was captured after 7 days of treatment. The root length (B), contents of chlorophyll (C), and malondialdehyde (MDA) (D) changes subjected to $200 \mathrm{mM} \mathrm{NaCl}$ (Salt) and absence of $\mathrm{NaCl}$ (Control) in transgenic and WT plants after 12 days of treatment. All data presented as means $\pm \mathrm{SE}, *$, Means differ $p<0.05$. 
Together, our results were strongly supportive of SpPKE1 OE plants, which confer salt stress tolerance in both tomato and tobacco.

\section{Discussion}

In our study, major observations regarding SIPKE1 and SpPKE1 included their expression in flowers and their negative regulation by ABA and abiotic stresses (Figures 3 and 4). SpPKE1 was a cytoplasm protein (Figure 2), and their OEs as transgenes enhance salt tolerance (Figures 5 and 6). Therefore, PKE1 was down-regulated by ABA, and drought stress enhanced salt stress tolerance.

\subsection{PKE1 Gene Sequence Diversity between Solanum Species and Involvement in Abiotic Stress}

Domesticating and growing plants as crops can present both advantages and disadvantages. Selecting specific desirable traits, such as high yield, can increase crop productivity, but other important traits, such as abiotic resistance, might be lost. It might induce vulnerability of crops to different stresses. Researchers often use wild relatives of crops to reduce these vulnerabilities. In our study, PKE1 was isolated from drought-resistant (S. pennellii LA0716) and cultivated species (S. lycopersicum cv. M82). The amino acid sequences of SpPKE1 and SIPKE1 shared high similarity, and the promoter cis-element of SPPKE1 and SIPKE1 had three differentiations (Figure 1 and Table 1). This finding implies that PKE1 is a protein that shows evolutionary trace between S. lycopersicum and S. pennellii.

PKE1 is a proline-, lysine-, and glutamic-rich protein (Figure 1A), and single domain in proteins such as proline-rich and lysine-rich protein have been reported to have important functions on abiotic tolerance [16-18]. It suggests that PKE has been involved in plant abiotic response. The proline-rich proteins (PRP) are initially defined as proteins involved in response to wounding [19]. A HyPRP1 gene in tomato plays a negative role in abiotic stress tolerance [14]. Heterologous expression of a lysine-rich protein gene $S B g L R$ in potato can significantly increase maize salt resistance [20]. Moreover, both the promoter of SPPKE1 and SIPKE1 had an MYB and MYC cis-element (Table 1). The MYB and MYC proteins are major transcription factors that play significant roles in plant defenses against various stresses [21-29]. These findings, together with our results, show that the MYB or MYC transcription factor may directly regulate PKE1 to confer abiotic stresses.

\subsection{PKE1 Down-Regulated by Abiotic Stresses and Enhance Salt Tolerance}

In most cases, the suppression of negative regulators or enhancement of positive regulators of ABA will confer abiotic tolerance [5,14,30-33]. However, reports about this topic provide different conclusions. A wheat zinc finger gene TaCHP was downregulated by ABA and salinity stress but enhanced stress tolerance by promoting centromere-binding factor 3 and DREB2A expression [34]. PKE1 functions similarly with TaCHP. PKE1 was downregulated by ABA and drought treatment (Figure 4). Salt tolerance in transgenic PKE1 OE plants significantly increased, compared with that of WT plants (Figures 5 and 6). The molecular mechanisms, regarding how the OE of negative regulators enhances salt tolerance, remain to be elucidated.

PKE1 can bind to F-box proteins [35].This is a clue for understanding the molecular mechanisms of the negative regulator PKE1 in enhancing salt tolerance in tobacco. F-box proteins are involved in post-transcriptional regulation by targeted protein ubiquitination [36]. F-box protein gene plays an important role in abiotic stress [37-40] and plant miRNA function in plant [41]. For example, an F-box protein DOR inhibits the ABA-induced stomatal closure under drought stress in Arabidopsis [39], and another F-box protein MAX plays an important role in the regulation of plant growth and development and in response to abiotic stress conditions [38]. The high or constant expression of PKE1 in reproductive tissues implies its special function in salt tolerance at the reproductive stage (Figure $3 \mathrm{~A}, \mathrm{~B}$ ). The result coincides with the hypermethylation of PKE1 DNA sequences in leaf rather than that during fruit development (Figure 3C), because DNA methylation inhibits gene expression [42]. DNA methylation plays a crucial role in plant organs and genotypes specific for regulating gene expression responsive to environmental stress, and it is a highly important regulatory mechanism for plant adaptation to 
environmental stresses [43-47]. This condition leads to the problem of identifying the cause of PKE1 hypermethylation in leaf but not in reproductive organs and implies that PKE1 confers tolerance to salt stress not only in the seedlings but also in the reproductive stage. These findings, together with the result that PKE1 can bind to F-box proteins, show that the PKE1 modulates the salt tolerance involved in post-transcriptional regulation.

\section{Materials and Methods}

\subsection{Plant Materials and Growth Conditions}

Tomato plants (S. pennellii LA0716 and S. lycopersicum cv. M82) were grown in a greenhouse under a $16 \mathrm{~h}$ light $/ 8 \mathrm{~h}$ dark regime at approximately $25^{\circ} \mathrm{C}$. At the six-leaf stage the seedlings were treated with drought, methyl viologen (MV) stress, and different hormones for PKE1 stress-responsive expression analysis. Under drought dehydration (DH) stress, the seedlings, removed from the soil, were placed on a filter paper. For MV and hormone treatments, the seedlings were sprayed with solutions containing $100 \mu \mathrm{M}$ MV, $100 \mu \mathrm{M}$ ABA, $100 \mu \mathrm{M}$ of gibberellic acid $\left(\mathrm{GA}_{3}\right), 100 \mu \mathrm{M} \mathrm{SA}, 100 \mu \mathrm{M}$ ethephon (Eth; an ethylene releaser), or distilled water (control). PKE1 expression was validated in the different organs of S. pennellii and S. lycopersicum cv. M82 at the six-leaf stage of seedlings. Then leaves were collected at designated time points, and different tissues were immediately frozen in liquid nitrogen and stored at $-80^{\circ} \mathrm{C}$ until use.

\subsection{Gene Isolation, Vector Construction, and Genetic Transformation}

Tomato PKE1 (SpPKE1: Sopen05g032700; SIPKE1: Solyc05g054210, http://solgenomics.net/, accessed on: 18 May 2019) was isolated from S. pennellii and S. lycopersicum cv. M82, respectively, the vector construction and genetic transformation were described as our previous study [35]. Briefly, the 35S-SpPKE1 and RNAi plasmid was transformed into tomato cultivar M82 and tobacco (Nicotiana nudicaulis) by Agrobacterium tumefaciens (strain C58)-mediated transformation. After screening the regenerated shoots on the selection medium containing kanamycin, the transgenic plants were further verified via PCR with genomic DNA as template using $35 S$ promoter forward and gene-specific reverse primers (Table S2).

\subsection{Bioinformatics Analysis}

Exons and introns were identified by comparing the genomic DNA and cDNA sequences by using Gene Structure Display Server (http://gsds.cbi.pku.edu.cn, accessed on: 18 May 2019) [48]. Homologous proteins of PKE1 were collected from the EBI database (http://www.ebi.ac.uk/, accessed on: 18 May 2019) using BLASTP. A phylogenetic tree was constructed using the neighbor-joining (NJ) method with MEGA (version 5.05) software [49]. The DNA methylation level of PKE1 was analyzed based on the tomato epigenome database (http://ted.bti.cornell.edu/epigenome/, accessed on: 18 May 2019) [50] by comparing the cytosine (C) and methylcytosine $(5 \mathrm{mC})$ of the genomes; the cytosine methylation ratio $=5 \mathrm{mC} /(5 \mathrm{mC}+\mathrm{C})$. The PKE1 promoter sequences were isolated from BLASTN search by using the PKE1 gene sequence queries against the tomato whole genome scaffolds (version 2.40) and S. pennellii WGS chromosome data at the SGN website (https://solgenomics.net/, accessed on: 18 May 2019). The promoter sequences (1.5 kb upstream of 5' UTR) of SpPKE1 and SIPKE1 were submitted to the PlantCARE database (http://bioinformatics.psb.ugent.be/webtools/plantcare/html/, accessed on: 18 May 2019) for cis-element prediction.

\subsection{Subcellular Localization of SPPKE1}

SpPKE1 coding region (without stop codon) was amplified by PCR from the S. pennellii LA0716 cDNA with primers containing KpnI and BamHI restriction sites (Table S2) for subcellular localization analysis. The PCR product was cloned into the pMD18-T vector (TaKaRa, Shiga, Japan), and sequenced. The correct sequence of SpPKE1 in plasmid was digested with KpnI and BamHI, and the fragment 
was fused to the $35 \mathrm{~S}$ promoter with fusion construction of enhanced green fluorescent protein (EGFP) into the KpnI and BamHI-digested pCAMBIA1391 vector [51]. The resulting 35S:SpPKE1-EGFP fusion construct with the GFP alone (35S-EGFP) was bombarded into BY-2 (N. tabacum cv. Bright Yellow 2) tobacco cells by using Biolistic PDS-1000 (Bio-Rad, Hercules, CA, USA). All samples were observed under a Leica TCSST2 confocal laser microscope (Zeiss, LSM510, Oberkochen, Germany) after $24 \mathrm{~h}$ of bombardment.

\subsection{RNA Isolation and Quantitative Reverse Transcription-PCR ( $q R T-P C R$ )}

Gene expression patterns were examined by isolating total RNA by using TRIzol solution (Sangon, Shanghai, China). DNase I-treated total RNA was used for first-strand cDNA synthesis, which adopted a PrimeScript RT reagent Kit (TaKaRa, Dalian, China) according to the manufacturer's instructions. The resulting cDNA was used for RT-PCR, which was performed on CFX96 (Bio-Rad, USA) with Eva Green SMX (Bio-Rad) by employing primers specific for genes as shown in Table S2. PCR amplification consisted of an initial incubation at $94{ }^{\circ} \mathrm{C}$ for $5 \mathrm{~min}$, followed by 40 cycles of $94^{\circ} \mathrm{C}$ for $10 \mathrm{~s}, 58^{\circ} \mathrm{C}$ for $15 \mathrm{~s}$, and $72{ }^{\circ} \mathrm{C}$ for $20 \mathrm{~s}$. Data was gathered during the extension step. Melting-curve acquisition and analysis was performed on cycler. Each sample included three replicates, and each assayed sample represented three independently collected samples. Data was normalized against the reference $\beta$-actin gene (Solyc11g005330.1.1).

\subsection{Salt Tolerance Testing of Transgenic Plants}

After anti-kanamycin analysis [52] and PCR (35S promoter forward and gene-specific reverse primers) confirmation, the resulted uniform-sized $\mathrm{T}_{3}$ homozygous at three-leaf stage tomato seedlings [35] were transplanted into cylindrical pots (Diameter: $8 \mathrm{~cm}$, Height: $8 \mathrm{~cm}$ ) and nourished to grow until the four-leaf stage for salt treatment, in order to evaluate salt tolerance of transgenic tomato lines. Salt stress was initiated by watering $200 \mathrm{mM} \mathrm{NaCl}$. After $14 \mathrm{~d}$ treatment, photos were taken and the survival rate was evaluated.

In order to simulate salt treatment, $\mathrm{T}_{2}$ transgenic tobacco [35] were selected by germinating seeds on $1 / 2 \mathrm{MS}$ medium containing $50 \mathrm{mg} / \mathrm{L}$ kanamycin. After germination, the germinant positive seedlings together with WT were transplanted in $1 / 2 \mathrm{MS}$ medium with $200 \mathrm{mM} \mathrm{NaCl}$ and grew for 12 days, the test was repeated 3 times. 12 days after salt treatment, the root length, chlorophyll, and malondialdehyde (MDA) content were measured. After removing the seedling from the medium, we used a ruler to measure the root length of each seedling. Chlorophyll content was measured using the Lichtenthaler's method [53]. Leaf tissues were ground under liquid nitrogen and extracted with $8 \mathrm{~mL}$ of $95 \%(v / v)$ ethyl alcohol. Absorption spectra were detected at 665 and $649 \mathrm{~nm}$. Chlorophyll was computed using the following equation: chlorophyll concentration $(\mathrm{mg} / \mathrm{mL})=(6.63 \times \mathrm{A} 665)+(18.08 \times \mathrm{A} 649)$, where $A$ refers to the absorbance at a specified wavelength. MDA was assayed for indirect evaluation of lipid peroxidation by using thiobarbituric acid as described previously [54].

\subsection{Statistical Analysis}

The results of salt tolerance testing and qRT-PCR experiments were displayed as mean \pm standard error (SE). Data was analyzed using variance by SAS software (version 8.0, SAS Institute, Cary, NC, USA), and statistical differences were compared using Fisher's least significant difference (LSD) test.

\section{Conclusions}

Wild species often show more tolerance to abiotic stress than their cultivated counterparts. Genes from wild species is the best resource of improving abiotic resistance in cultivated species. In this study, a tomato proline-, lysine-, and glutamic-rich type gene SpPKE1 was isolated from drought-resistant species (S. pennellii LA0716) enhanced the salt tolerance in cultivated tomato and tobacco. Moreover, expression and methylation analysis results indicated that the PKE1 involved in post-transcriptional regulation. 
Supplementary Materials: The following are available online at http://www.mdpi.com/1422-0067/20/10/2478/s1. Figure S1 SIPKE1 was responsive to drought stress in three genotypes (M82, IL2-5 and IL9-1) in microarray data [15]. Genes (FDR $<0.05$ and fold $\geq 2$ ) were identified as differentially expressed genes. Table S1 Sequence composition of SpPKE1 and SIPKE1. Table S2 Primer sequences used for vector construction and qRT-PCR analysis. File S1 Details of DNA methylation in PKE1 promoter and coding sequence.

Author Contributions: Writing—original draft and supervision, J.L.; Investigation and Data curation, C.C. and J.W.; Methodology, Y.P. and C.S.; Project administration, X.Z.

Funding: This work was supported by grant National Natural Science Foundation of China (No. 31872123), Chongqing Natural Science Foundation (No. cstc2018jcyjA0947 and No. cstc2018jcyjAX0730) and the Chongqing Social Enterprise and People's Livelihood Guarantee Science and Technology Innovation Special Project (cstc2017shms-zdyfx0025).

Conflicts of Interest: The authors declare no conflict of interest.

\section{References}

1. Costa, J.M.; Heuvelink, E. The Global Tomato Industry; CABI: Boston, MA, USA, 2018.

2. Sadashiva, A.T.; Singh, A.; Kumar, R.P.; Sowmya, V.; D'mello, D.P. Tomato. In Abiotic Stress Physiology of Horticultural Crops; Rao, N.K.S., Shivashankara, K.S., Laxman, R.H., Eds.; Springer: New Delhi, India, 2016; pp. 121-131.

3. Klay, I.; Pirrello, J.; Riahi, L.; Bernadac, A.; Cherif, A.; Bouzayen, M.; Bouzid, S. Ethylene response factor Sl-ERF.B.3 is responsive to abiotic stresses and mediates salt and cold stress response regulation in tomato. Sci. World J. 2014, 2014, 167681. [CrossRef]

4. Pan, I.C.; Li, C.W.; Su, R.C.; Cheng, C.P.; Lin, C.S.; Chan, M.T. Ectopic expression of an EAR motif deletion mutant of SIERF3 enhances tolerance to salt stress and Ralstonia solanacearum in tomato. Planta 2010, 232, 1075-1086. [CrossRef]

5. Hichri, I.; Muhovski, Y.; Clippe, A.; Zizkova, E.; Dobrev, P.I.; Motyka, V.; Lutts, S. SIDREB2, a tomato DEHYDRATION RESPONSIVE ELEMENT BINDING 2 transcription factor, mediates salt stress tolerance in tomato and Arabidopsis. Plant Cell Environ. 2015, 39, 62-79. [CrossRef] [PubMed]

6. Hichri, I.; Muhovski, Y.; Zizkova, E.; Dobrev, P.I.; Franco-Zorrilla, J.M.; Solano, R.; Lopez-Vidriero, I.; Motyka, V.; Lutts, S. The Solanum lycopersicum Zinc Finger2 cysteine-2/histidine-2 repressor-like transcription factor regulates development and tolerance to salinity in tomato and Arabidopsis. Plant Physiol. 2014, 164, 1967-1990. [CrossRef] [PubMed]

7. Orellana, S.; Yanez, M.; Espinoza, A.; Verdugo, I.; Gonzalez, E.; Ruiz-Lara, S.; Casaretto, J.A. The transcription factor SIAREB1 confers drought, salt stress tolerance and regulates biotic and abiotic stress-related genes in tomato. Plant Cell Environ. 2010, 33, 2191-2208. [CrossRef]

8. Huertas, R.; Rubio, L.; Cagnac, O.; Garcia-Sanchez, M.J.; Alche Jde, D.; Venema, K.; Fernandez, J.A.; Rodriguez-Rosales, M.P. The K+/H+ antiporter LeNHX2 increases salt tolerance by improving $\mathrm{K}+$ homeostasis in transgenic tomato. Plant Cell Environ. 2013, 36, 2135-2149. [CrossRef] [PubMed]

9. Rodriguez-Rosales, M.P.; Jiang, X.; Galvez, F.J.; Aranda, M.N.; Cubero, B.; Venema, K. Overexpression of the tomato $\mathrm{K}+/ \mathrm{H}+$ antiporter LeNHX2 confers salt tolerance by improving potassium compartmentalization. New Phytol. 2008, 179, 366-377. [CrossRef] [PubMed]

10. Olias, R.; Eljakaoui, Z.; Li, J.; De Morales, P.A.; Marin-Manzano, M.C.; Pardo, J.M.; Belver, A. The plasma membrane $\mathrm{Na}+\mathrm{H}+$ antiporter SOS1 is essential for salt tolerance in tomato and affects the partitioning of $\mathrm{Na}+$ between plant organs. Plant Cell Environ. 2009, 32, 904-916. [CrossRef]

11. Leidi, E.O.; Barragan, V.; Rubio, L.; El-Hamdaoui, A.; Ruiz, M.T.; Cubero, B.; Fernandez, J.A.; Bressan, R.A.; Hasegawa, P.M.; Quintero, F.J.; et al. The AtNHX1 exchanger mediates potassium compartmentation in vacuoles of transgenic tomato. Plant J. Cell Mol. Biol. 2010, 61, 495-506. [CrossRef]

12. Xin, S.; Yu, G.; Sun, L.; Qiang, X.; Xu, N.; Cheng, X. Expression of tomato SITIP2;2 enhances the tolerance to salt stress in the transgenic Arabidopsis and interacts with target proteins. J. Plant Res. 2014, 127, 695-708. [CrossRef]

13. Liu, B.; Ouyang, Z.; Zhang, Y.; Li, X.; Hong, Y.; Huang, L.; Liu, S.; Zhang, H.; Li, D.; Song, F. Tomato NAC transcription factor SISRN1 positively regulates defense response against biotic stress but negatively regulates abiotic stress response. PLoS ONE 2014, 9, e102067. [CrossRef] [PubMed] 
14. Li, J.; Ouyang, B.; Wang, T.; Luo, Z.; Yang, C.; Li, H.; Sima, W.; Zhang, J.; Ye, Z. HyPRP1 Gene Suppressed by Multiple Stresses Plays a Negative Role in Abiotic Stress Tolerance in Tomato. Front. Plant Sci. 2016, 7, 967. [CrossRef] [PubMed]

15. Gong, P.; Zhang, J.; Li, H.; Yang, C.; Zhang, C.; Zhang, X.; Khurram, Z.; Zhang, Y.; Wang, T.; Fei, Z.; et al. Transcriptional profiles of drought-responsive genes in modulating transcription signal transduction, and biochemical pathways in tomato. J. Exp. Bot. 2010, 61, 3563-3575. [CrossRef] [PubMed]

16. Petersen, J.; Eriksson, S.K.; Harryson, P.; Pierog, S.; Colby, T.; Bartels, D.; Rohrig, H. The lysine-rich motif of intrinsically disordered stress protein CDeT11-24 from Craterostigma plantagineum is responsible for phosphatidic acid binding and protection of enzymes from damaging effects caused by desiccation. J. Exp. Bot. 2012, 63, 4919-4929. [CrossRef] [PubMed]

17. Pitzschke, A.; Xue, H.; Persak, H.; Datta, S.; Seifert, G.J. Post-Translational Modification and Secretion of Azelaic Acid Induced 1 (AZI1), a Hybrid Proline-Rich Protein from Arabidopsis. Int. J. Mol. Sci. 2016, $17,85$. [CrossRef]

18. Mellacheruvu, S.; Tamirisa, S.; Vudem, D.R.; Khareedu, V.R. Pigeonpea hybrid-proline-rich protein (CcHyPRP) confers biotic and abiotic stress tolerance in transgenic rice. Front. Plant Sci. 2016, 6, 1167. [CrossRef] [PubMed]

19. Chen, J.; Varner, J.E. Isolation and characterization of cDNA clones for carrot extensin and a proline-rich 33-kDa protein. Proc. Natl. Acad. Sci. USA 1985, 82, 4399-4403. [CrossRef]

20. Wang, M.; Liu, C.; Li, S.; Zhu, D.; Zhao, Q.; Yu, J. Improved nutritive quality and salt resistance in transgenic maize by simultaneously overexpression of a natural lysine-rich protein gene, SBgLR, and an ERF transcription factor gene, TSRF1. Int. J. Mol. Sci. 2013, 14, 9459-9474. [CrossRef]

21. Fang, Q.; Wang, Q.; Mao, H.; Xu, J.; Wang, Y.; Hu, H.; He, S.; Tu, J.; Cheng, C.; Tian, G.; et al. AtDIV2, an R-R-type MYB transcription factor of Arabidopsis, negatively regulates salt stress by modulating ABA signaling. Plant Cell Rep. 2018, 37, 1499-1511. [CrossRef]

22. Wu, J.; Jiang, Y.; Liang, Y.; Chen, L.; Chen, W.; Cheng, B. Expression of the maize MYB transcription factor ZmMYB3R enhances drought and salt stress tolerance in transgenic plants. Plant Physiol. Biochem. 2019, 137, 179-188. [CrossRef]

23. Gao, F.; Zhou, J.; Deng, R.Y.; Zhao, H.X.; Li, C.L.; Chen, H.; Suzuki, T.; Park, S.U.; Wu, Q. Overexpression of a tartary buckwheat R2R3-MYB transcription factor gene, FtMYB9, enhances tolerance to drought and salt stresses in transgenic Arabidopsis. J. Plant Physiol. 2017, 214, 81-90. [CrossRef]

24. Shen, X.J.; Wang, Y.Y.; Zhang, Y.X.; Guo, W.; Jiao, Y.Q.; Zhou, X.A. Overexpression of the Wild Soybean R2R3-MYB Transcription Factor GsMYB15 Enhances Resistance to Salt Stress and Helicoverpa Armigera in Transgenic Arabidopsis. Int. J. Mol. Sci. 2018, 19, 3958. [CrossRef]

25. Huang, Y.; Zhao, H.; Gao, F.; Yao, P.; Deng, R.; Li, C.; Chen, H.; Wu, Q. A R2R3-MYB transcription factor gene, FtMYB13, from Tartary buckwheat improves salt/drought tolerance in Arabidopsis. Plant Physiol. Biochem. 2018, 132, 238-248. [CrossRef]

26. Wei, Q.; Luo, Q.; Wang, R.; Zhang, F.; He, Y.; Zhang, Y.; Qiu, D.; Li, K.; Chang, J.; Yang, G.; et al. A Wheat R2R3-type MYB Transcription Factor TaODORANT1 Positively Regulates Drought and Salt Stress Responses in Transgenic Tobacco Plants. Front. Plant Sci. 2017, 8, 1374. [CrossRef]

27. Yu, Y.; Ni, Z.; Chen, Q.; Qu, Y. The wheat salinity-induced R2R3-MYB transcription factor TaSIM confers salt stress tolerance in Arabidopsis thaliana. Biochem. Biophys. Res. Commun. 2017, 491, 642-648. [CrossRef]

28. Kim, B.G.; Evans, H.M.; Dubins, D.N.; Chalikian, T.V. Effects of Salt on the Stability of a G-Quadruplex from the Human c-MYC Promoter. Biochemistry 2015, 54, 3420-3430. [CrossRef]

29. Feng, H.L.; Ma, N.N.; Meng, X.; Zhang, S.; Wang, J.R.; Chai, S.; Meng, Q.W. A novel tomato MYC-type ICE1-like transcription factor, SIICE1a, confers cold, osmotic and salt tolerance in transgenic tobacco. Plant Physiol. Biochem. 2013, 73, 309-320. [CrossRef]

30. Oh, S.J.; Song, S.I.; Kim, Y.S.; Jang, H.J.; Kim, S.Y.; Kim, M.; Kim, Y.K.; Nahm, B.H.; Kim, J.K. Arabidopsis $\mathrm{CBF} / \mathrm{DREB} 1 \mathrm{~A}$ and $\mathrm{ABF} 3$ in transgenic rice increased tolerance to abiotic stress without stunting growth. Plant Physiol. 2005, 138, 341-351. [CrossRef]

31. Pandey, G.K.; Grant, J.J.; Cheong, Y.H.; Kim, B.G.; Li, L.; Luan, S. ABR1, an APETALA2-domain transcription factor that functions as a repressor of ABA response in Arabidopsis. Plant Physiol. 2005, 139, 1185-1193. [CrossRef] 
32. Zhang, Y.; Yang, C.; Li, Y.; Zheng, N.; Chen, H.; Zhao, Q.; Gao, T.; Guo, H.; Xie, Q. SDIR1 is a RING finger E3 ligase that positively regulates stress-responsive abscisic acid signaling in Arabidopsis. Plant Cell 2007, 19, 1912-1929. [CrossRef]

33. Ziaf, K.; Loukehaich, R.; Gong, P.; Liu, H.; Han, Q.; Wang, T.; Li, H.; Ye, Z. A multiple stress-responsive gene ERD15 from Solanum pennellii confers stress tolerance in tobacco. Plant Cell Physiol. 2011, 52, 1055-1067. [CrossRef]

34. Li, C.; Lv, J.; Zhao, X.; Ai, X.; Zhu, X.; Wang, M.; Zhao, S.; Xia, G. TaCHP: A wheat zinc finger protein gene down-regulated by abscisic acid and salinity stress plays a positive role in stress tolerance. Plant Physiol. 2010, 154, 211-221. [CrossRef]

35. Li, J.; Wang, Y.; Wei, J.; Pan, Y.; Su, C.; Zhang, X. A tomato proline-, lysine-, and glutamic-rich type gene SpPKE1 positively regulates drought stress tolerance. Biochem. Biophys. Res. Commun. 2018, 499, 777-782. [CrossRef]

36. Skaar, J.R.; Pagan, J.K.; Pagano, M. Mechanisms and function of substrate recruitment by F-box proteins. Nat. Rev. Mol. Cell Biol. 2013, 14, 369-381. [CrossRef]

37. Yan, Y.-S.; Chen, X.-Y.; Yang, K.; Sun, Z.-X.; Fu, Y.-P.; Zhang, Y.-M.; Fang, R.-X. Overexpression of an F-box protein gene reduces abiotic stress tolerance and promotes root growth in rice. Mol. Plant 2011, 4, $190-197$. [CrossRef]

38. Bu, Q.; Lv, T.; Shen, H.; Luong, P.; Wang, J.; Wang, Z.; Huang, Z.; Xiao, L.; Engineer, C.; Kim, T.H. Regulation of drought tolerance by the F-box protein MAX2 in Arabidopsis. Plant Physiol. 2014, 164, 424-439. [CrossRef]

39. Zhang, Y.; Xu, W.; Li, Z.; Deng, X.W.; Wu, W.; Xue, Y. F-box protein DOR functions as a novel inhibitory factor for abscisic acid-induced stomatal closure under drought stress in Arabidopsis. Plant Physiol. 2008, 148, 2121-2133. [CrossRef]

40. Zhou, S.; Sun, X.; Yin, S.; Kong, X.; Zhou, S.; Xu, Y.; Luo, Y.; Wang, W. The role of the F-box gene TaFBA1 from wheat (Triticum aestivum L.) in drought tolerance. Plant Physiol. Biochem. 2014, 84, 213-223. [CrossRef]

41. Lang, P.; Christie, M.; Dogan, E.; Schwab, R.; Hagmann, J.; Van de Weyer, A.-L.; Weigel, D. A Role For The F-Box Protein HAWAIIAN SKIRT In Plant miRNA Function. bioRxiv 2017, 123703. [CrossRef]

42. Razin, A.; Cedar, H. DNA methylation and gene expression. Microbiol. Rev. 1991, 55, 451-458.

43. Verhoeven, K.J.; Jansen, J.J.; Van Dijk, P.J.; Biere, A. Stress-induced DNA methylation changes and their heritability in asexual dandelions. New Phytol. 2010, 185, 1108-1118. [CrossRef]

44. Wang, W.-S.; Pan, Y.-J.; Zhao, X.-Q.; Dwivedi, D.; Zhu, L.-H.; Ali, J.; Fu, B.-Y.; Li, Z.-K. Drought-induced site-specific DNA methylation and its association with drought tolerance in rice (Oryza sativa L.). J. Exp. Bot. 2010, 62, 1951-1960. [CrossRef]

45. Karan, R.; DeLeon, T.; Biradar, H.; Subudhi, P.K. Salt stress induced variation in DNA methylation pattern and its influence on gene expression in contrasting rice genotypes. PLoS ONE 2012, 7, e40203. [CrossRef]

46. Garg, R.; Chevala, V.N.; Shankar, R.; Jain, M. Divergent DNA methylation patterns associated with gene expression in rice cultivars with contrasting drought and salinity stress response. Sci. Rep. 2015, 5, 14922. [CrossRef]

47. Herman, J.J.; Sultan, S.E. DNA Methylation Mediates Genetic Variation for Adaptive Transgenerational Plasticity. Proc. Biol. Sci. 2016, 283, 20160988. [CrossRef]

48. Guo, A.; Zhu, Q.; Chen, X.; Luo, J. GSDS: A gene structure display server. Yi Chuan= Hereditas/Zhongguo Yi Chuan Xue Hui Bian Ji 2007, 29, 1023-1026. [CrossRef]

49. Tamura, K.; Peterson, D.; Peterson, N.; Stecher, G.; Nei, M.; Kumar, S. MEGA5: Molecular evolutionary genetics analysis using maximum likelihood, evolutionary distance, and maximum parsimony methods. Mol. Biol. Evol. 2011, 28, 2731-2739. [CrossRef]

50. Zhong, S.; Fei, Z.; Chen, Y.R.; Zheng, Y.; Huang, M.; Vrebalov, J.; McQuinn, R.; Gapper, N.; Liu, B.; Xiang, J.; et al. Single-base resolution methylomes of tomato fruit development reveal epigenome modifications associated with ripening. Nat. Biotechnol. 2013, 31, 154-159. [CrossRef]

51. Li, J.; Sima, W.; Ouyang, B.; Wang, T.; Ziaf, K.; Luo, Z.; Liu, L.; Li, H.; Chen, M.; Huang, Y.; et al. Tomato SIDREB gene restricts leaf expansion and internode elongation by downregulating key genes for gibberellin biosynthesis. J. Exp. Bot. 2012, 63, 6407-6420. [CrossRef]

52. Sunseri, F.; Fiore, M.; Mastrovito, F.; Tramontano, E. In vivo selection and genetic analysis for kanamycin resistance in transgenic eggplant (Solanum melongena L.). J. Genet. Breed. 1993, 47, 299. 
53. Lichtenthaler, H.K. Chlorophylls and carotenoids: Pigments of photosynthetic biomembranes. Methods Enzymol. 1987, 148, 350-382.

54. Hodges, D.M.; DeLong, J.M.; Forney, C.F.; Prange, R.K. Improving the thiobarbituric acid-reactive-substances assay for estimating lipid peroxidation in plant tissues containing anthocyanin and other interfering compounds. Planta 1999, 207, 604-611. [CrossRef]

(c)

(C) 2019 by the authors. Licensee MDPI, Basel, Switzerland. This article is an open access article distributed under the terms and conditions of the Creative Commons Attribution (CC BY) license (http://creativecommons.org/licenses/by/4.0/). 